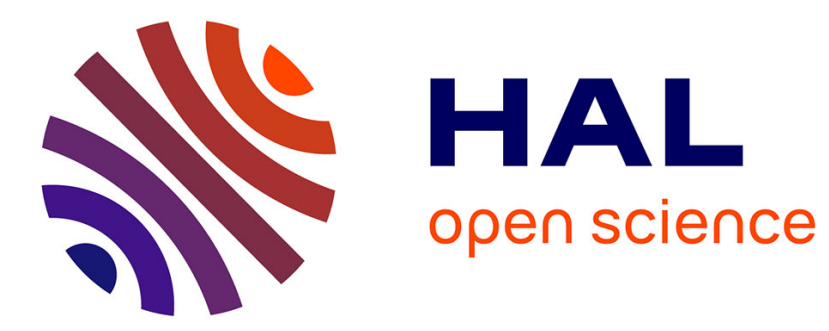

\title{
Psychometric properties of a French version of the junior temperament and character inventory
}

\author{
M. Asch, S. Cortese, F. Perez Diaz, A. Pelissolo, V. Aubron, S. Orejarena, E.
} Acquaviva, Marie-Christine Mouren, G. Michel, P. Gorwood, et al.

\section{- To cite this version:}

M. Asch, S. Cortese, F. Perez Diaz, A. Pelissolo, V. Aubron, et al.. Psychometric properties of a French version of the junior temperament and character inventory. European Child and Adolescent Psychiatry, 2009, 18 (3), pp.144-153. 10.1007/s00787-008-0713-9 . hal-00478071

\section{HAL Id: hal-00478071 https://hal.science/hal-00478071}

Submitted on 30 Apr 2010

HAL is a multi-disciplinary open access archive for the deposit and dissemination of scientific research documents, whether they are published or not. The documents may come from teaching and research institutions in France or abroad, or from public or private research centers.
L'archive ouverte pluridisciplinaire HAL, est destinée au dépôt et à la diffusion de documents scientifiques de niveau recherche, publiés ou non, émanant des établissements d'enseignement et de recherche français ou étrangers, des laboratoires publics ou privés. 
M. Asch

S. Cortese

F. Perez Diaz

A. Pelissolo

V. Aubron

S. Orejarena

E. Acquaviva

Marie-Christine Mouren

G. Michel

P. Gorwood

D. Purper-Ouakil

Received: 3 January 2008

Accepted: 18 June 2008

Published online: 6 February 2009

M. Asch · S. Cortese - V. Aubron

S. Orejarena $\cdot$ E. Acquaviva

M.C. Mouren · D. Purper-Ouakil ( $\square$ )

AP-HP, Service de Psychopathologie de

l'Enfant et de l'Adolescent

Hôpital Robert Debré

48 bd Sérurier

75019 Paris, France

E-Mail: diane.purper-ouakil@orange.fr

F. Perez Diaz · A. Pelissolo

CNRS UMR7593, Hôpital de la Salpêtrière

47 bd de l'hôpital

75013 Paris, France

A. Pelissolo

Service de Psychiatrie

AP-HP, Hôpital de la Salpêtrière

47 bd de l'hôpital

75013 Paris, France

M.C. Mouren · P. Gorwood

D. Purper-Ouakil

INSERM U 675 Analyse phénotypique

développementale et génétique des

comportements addictifs

Faculté Xavier Bichat, 75018 Paris, France

\section{Psychometric properties of a French version of the junior temperament and character inventory}

Abstract The junior temperament and character inventory (JTCI) has been developed for the assessment of temperament and character dimensions in childhood based on Cloninger's model of personality. We evaluated the psychometric proprieties of a French child and parent-rated version of the JTCI based on a previous German version, and assessed the correlations between the JTCI dimension scores and the scores on the child behavior checklist (CBCL) in a community sample of French children and adolescents aged $10-16$ years. We used data from 452 child-rated and 233 -parent-rated JCTI. The psychometric properties (internal

\section{G. Miche}

Bordeaux 2 Laboratoire de Psychologie EA

«Santé et qualité de vie»

Université Victor Segalen

3 ter Place de la Victoire

33076 Bordeaux Cedex, France

V. Aubron

Université François Rabelais

Tours, France consistency and external validity in relation to the emotionality activity sociability (EAS) questionnaire) of the French JTCI were adequate in the parent-rated version. The parent-rated JTCI had overall better psychometric qualities than the child-rated version, but for both versions of the JTCI the confirmatory factor analysis showed low fit between the observed data and the original model. Dimensions of the EAS model were significantly correlated with the temperament scales of the JTCI. Further studies are required to improve the psychometric properties of the child-rated JTCI, and to provide insight about lacking fit of our data with the theoretical model.

Key words children temperament - questionnaires factor analysis

\section{Introduction}

Cloninger et al. [11] developed a psychobiological model of temperament and character to describe the underlying biogenetic structure of personality. Cloninger et al. [11] initially hypothesized that the temperamental dimensions of personality are highly heritable and stable, while character facets are influenced by social learning. However, recent twin studies by the same research group showed that that temperament and character dimensions are equally heritable [20]. Current evidence suggests that the distinction between temperament and character is 
based on differences in the underlying forms of learning and memory: temperament measures individual differences in procedural learning (habit learning of emotional responses), whereas character measures individual differences in prepositional learning of goals and values [9].

Cloninger's model includes four temperamental dimensions (namely novelty seeking (NS), harm avoidance (HA), reward dependence (RD), and persistence $(\mathrm{P})$ ), and three character facets (i.e. selfdirectedness (SD), cooperativeness (C), and self-transcendence (ST)). NS is defined as a tendency to respond actively to novel stimuli, with frequent exploratory activity in response to novelty or impulsive decisionmaking. HA is viewed as behavioural inhibition triggered by potential harm or danger and implies a heritable bias toward being cautious, apprehensive, and overly pessimistic. $\mathrm{RD}$ is linked to the maintenance or continuation of ongoing behaviours, and is manifest as sentimentality, social attachment and dependence. $\mathrm{P}$ refers to a heritable tendency to be perseverant despite fatigue and frustration.

The temperament and character inventory (TCI) was developed by Cloninger et al. [10] to assess the above mentioned seven dimensions. The validity and reliability of the original American version of the TCI, as well as translated versions, have been described in previous studies [5, 23, 37, 42], including a validation study of the French TCI [37]. In order to assess personality dimensions in childhood, Luby et al. developed the junior temperament and character inventory (JTCI) for children aged between 9 and 13 years [34]. The JTCI has been adapted and validated in several languages, including Swedish, Korean, Israeli, and German [8, 21, $22,35]$. It has been used in several published studies to gain insight into the temperament of children and adolescents, in particular from a genetic and developmental point of view [3, 31-33, 38, 41, 49].

Currently, no French version of the JTCI is validated. A preliminary study using an adaptation of the French TCI items for preadolescents showed low internal consistency in several dimensions [15]. Therefore, further investigations of the biopsychosocial model of personality, with assessments specifically validated in the pediatric population were necessary. Moreover, because of evidence showing the TCI had discriminative power for psychopathological conditions and that some dimensions may differentiate broad categories of disorders, [11, 12, 42] correlations between the dimensions of JTCI and clinical symptoms of psychopathology needed further investigation $[21,28,30,40,43]$.

In light of these considerations, we developed a French adapted version of the JTCI using items from the German version of JTCI [21]. We chose to translate the German JTCI because it was available at the time we started our study and had undergone a series of psychometric analyses [21]. Compared with the original US version, several items were taken out in the German JTCI (JTCI 12-18), because of misinterpretations. The version we translated into French had 84 items and 4 scores ("yes, mostly yes, mostly no, no").

The aims of the present study were: (1) to assess the psychometric proprieties of this French adapted version of the JTCI in a non clinical sample of French adolescents; (2) to obtain French data for scales of the JTCI in a community sample; (3) to correlate the JTCI dimension scores to the scores obtained on other questionnaires assessing temperament dimensions and psychopathological symptoms.

\section{Method}

\section{Development of a French adaptation of the junior $\mathrm{TCl}$}

The German adapted version of the JTCI was first translated into French by a bilingual clinician. Second, it was translated back into German by a translator. The translated back version was compared to the original German version. The parent version of the JTCI has been created in converting all questions to the third person ("does your child ... ?"). Both child and parent-rated questionnaires were tested on a small clinical sample to assess their acceptability and comprehensibility. This pilot study included 10 children from our outpatient clinic, as well as their parents (the children had various psychopathological disorders, excluding mental retardation and pervasive developmental disorders). Children and parents filled out the questionnaires in presence of the investigator who assessed feasibility and correct understanding by a systematic review of all items. As a result, we modified the wording of several items which appeared to be unclear or ambiguous. No changes were made as regards the structure of the questionnaire or the temperament/ character dimension assessed by a particular item.

\section{Instruments}

To explore the concurrent validity of the JTCI, we used the emotionality activity sociability (EAS) questionnaire, which is a 20 -item temperament questionnaire assessing four basic dimensions: Emotionality, Activity, Sociability and Shyness. Parentrated and child rated versions were translated into French $[4,6,19]$.

We also used the Child Behavior Checklist (CBCL), a 113 item parent-report questionnaire on general behavioural and affective characteristics of children 
available in a French version $[1,17]$. The CBCL has two subscales: internalized disorders with a predominance of anxious or depressive symptoms, and externalized disorders combining motor instability, impulsivity and oppositional manifestations. A total score of 41 or more is an indicator of psychopathology.

\section{Subjects}

Subjects and their parents were recruited in a French secondary school attended by children from middleclass families. Parents received a letter explaining the goals of the study and gave written informed consent. Parents and children were asked to independently complete the different questionnaires. Children received the child-rated version of the French JTCI and the child-scored EAS. Parents received the parental versions of both JTCI and EAS and the CBCL.

Two hundred and fourteen subjects aged from 10 to 16 (51.9\% boys, $48.1 \%$ girls recruited from another sample in a French secondary school from another region completed the child version of the JTCI and were subsequently combined to the first sample for the factor analysis of the Child JTCI version subscale only.

\section{Demographic characteristics}

All socio-economic classes were represented. We used the French classification INSEE [27] of the socioeconomic status with eight categories from 0 to 7 to determine the profession of the parent who rated the questionnaire (0: no professional activity, 1: farmers, 2: craftsmen, storekeepers, managers, 3: executives and higher intellectual professionals 4: intermediate professions, 5: Employees, 6: Workers, 7: retired). The results were: $0: 9.5 \% ; 1: 7.8 \% ; 2: 3.3 \% ; 3: 9.5 \% ; 4$ : 14.8\%; 5: 19.3\%; 6: 31.3\%, 7: 4.5\%.

\section{Statistical analysis}

Internal consistency for each of the seven dimensions from both parent and child-rated questionnaires, was assessed using the Cronbach's alpha coefficient. Confirmatory factor analysis (CFA) was used to verify the factorial structure of each of the two questionnaires (Proc Calis, SAS) [39]. The confirmed structure was the one with 7 non-orthogonal dimensions. In the two questionnaires, factorial scores differences for the 7 dimensions have been analysed using a two way ANOVA with the factors Age and Gender. Bravais-Pearson's correlations were used to analyse the relationships between the scores for the seven dimensions, between parents and children questionnaires, and to estimate the external validity by comparison to other scales such as EAS and CBCL. We estimated sample size according to published recommendations requiring that the minimum number of subjects in the factorial analysis should be 2.5-3 times the number of the items of the test $[25,36]$. Refering tho these criteria, we needed a mimimum of 210-250 subjects. Therefore, our final sample was adequate to perform the statistical analysis with a sufficient statistical power.

\section{Results}

\section{Sample}

Our main sample was recruited in an initial population of 312 children registered at school. In this sample, 69 families did not return the questionnaires or returned uncompleted questionnaires. From the 243 participating children ( $36.6 \%$ boys, $63.4 \%$ girls) aged from 10 to 16 (mean age $12.9 \pm 1.3$ ), 238 children JTCI and 233 parents JTCI were usable for our study (questionnaires with more than ten unanswered items were excluded). Data from a second sample of 214 families with only child-rated JTCI was combined with the main sample. Therefore, analyses of the child rated version were carried out in a final sample of 452 children. Numbers of non-responders in the second sample, as well as socio-demographic characteristics of non responders were not available.

\section{JTCI Scores}

JTCI scores for each dimension are shown in Table 1. On the two way ANOVA analysis with factors age and gender, we found significantly higher scores in girls for HA, RD, C and ST. No significant difference was found in JTCI scores according to age. When mean JTCI scores from children and parents were compared with a paired mean comparison $t$ test, significant differences appeared only for $\mathrm{C}(t=2.06$; $P=0.04)$ and ST $(t=3.25 ; P=0.001)$.

\section{Correlations between parents and children on JTCl scores}

Inter-scale correlations between parents and childrenrated questionnaire are shown in Table 1 and were highest for C (0.51) and NS (0.51) and lowest for ST (0.39).

\section{Internal consistency}

The Cronbach alpha coefficients for each dimension of parent and child-rated versions of the JTCI are 
Table 1 JTCl scores, interscales correlations and internal consistencies

\begin{tabular}{llllll}
\hline Dimensions & $\begin{array}{l}\text { Number of } \\
\text { items }\end{array}$ & $\begin{array}{l}\text { JTCI-P Mean } \\
\text { (SD) }\end{array}$ & $\begin{array}{l}\text { JTCI-C Mean (SD) } \\
N=233\end{array}$ & $\begin{array}{l}\text { Parent/Child Correlations } \\
N=238\end{array}$ & $\begin{array}{l}\text { JTCI-P } \alpha \\
N=233\end{array}$ \\
\hline NS & 14 & $20.2(3.14)$ & $20.4(5.37)$ & $0.50^{*}$ & $\begin{array}{l}\text { JTCI-C } \alpha \\
N=452\end{array}$ \\
HA & 14 & $18.1(6.69)$ & $19.1(6.86)$ & $0.48^{*}$ & 0.75 \\
RD & 10 & $17.6(4.35)$ & $17.3(4.34)$ & $0.48^{*}$ & 0.81 \\
P & 8 & $12.9(5.11)$ & $13.7(4.01)$ & $0.48^{*}$ & 0.58 \\
SD & 14 & $26.7(6.09)$ & $25.9(5.9)$ & $0.41^{*}$ & 0.31 \\
C & 14 & $26.7(5.90)$ & $25.6(5.87)$ & $0.51^{*}$ & 0.82 \\
ST & 10 & $15.2(4.17)$ & $16.60(5.27)$ & $0.39^{*}$ & 0.76 \\
\end{tabular}

JTCI-P parent-rated junior temperament and character inventory, JTCI-C child-rated junior temperament and character inventory, SD standard deviation, $\alpha$ Cronbach's alpha, NS novelty seeking, HA harm avoidance, $R D$ reward dependence, $P$ persistence, SD self-directedness, $C$ cooperativeness, ST self-transcendence ${ }^{*} P<0.05$

listed in Table 1. All alpha coefficients for JTCI scores were above 0.70 except for RD and ST in the parentrated version (0.58 and 0.56) and for NS, ST, and RD in the children version.

\section{Factor analysis}

A CFA on the hypothesized factor structure was performed for each version of the JTCI. Results of the CFA for the parent-rated version and for the child- rated JTCI are shown in Tables 2 and 3, respectively. In this kind of analysis, a factor structure is explicitly hypothesized and is tested for its fit with the observed covariance matrix of the measured variables. Indicators of fit include a $\chi^{2}$ test to examine the hypothesis that the model is consistent with the pattern of covariation among the observed variables. A significant $\chi^{2}(P<0.05)$ implies that a significant amount of the observed covariance between measures is not explained by the model. The ratio between the model $\chi^{2}$ and degrees of freedom $(d f)$ has generally been

Table 2 Confirmatory factor analysis for the parent-rated JTCI $(N=233)$

\begin{tabular}{|c|c|c|c|c|c|c|c|}
\hline & NS & HA & $\mathrm{RD}$ & $P$ & C & SD & ST \\
\hline Item & 6 & 1 & 20 & 5 & 2 & 3 & 12 \\
\hline Loading & 0.52 & 0.31 & 0.20 & 0.45 & 0.38 & 0.54 & 0.26 \\
\hline Item & 8 & 9 & 32 & 10 & 4 & 7 & 14 \\
\hline Loading & 0.19 & 0.33 & 0.38 & 0.69 & 0.40 & 0.27 & 0.27 \\
\hline Item & 15 & 13 & 39 & 25 & 16 & 11 & 19 \\
\hline Loading & 0.52 & 0.31 & 0.20 & 0.45 & 0.38 & 0.54 & 0.26 \\
\hline Item & 21 & 17 & 44 & 40 & 22 & 18 & 23 \\
\hline Loading & 0.66 & 0.74 & 0.67 & 0.68 & 0.57 & 0.46 & 0.66 \\
\hline Item & 26 & 27 & 48 & 41 & 28 & 24 & 37 \\
\hline Loading & 0.42 & $0.08^{*}$ & $0.08^{*}$ & 0.79 & 0.60 & 0.48 & 0.40 \\
\hline Item & 30 & 31 & 63 & 45 & 33 & 29 & 53 \\
\hline Loading & 0.34 & 0.23 & 0.57 & 0.47 & 0.44 & 0.32 & 0.39 \\
\hline Item & 43 & 35 & 67 & 57 & 36 & 34 & 56 \\
\hline Loading & 0.42 & 0.72 & 0.36 & 0.52 & 0.25 & 0.38 & 0.25 \\
\hline Item & 51 & 47 & 68 & 77 & 46 & 38 & 66 \\
\hline Loading & 0.49 & 0.36 & 0.24 & 0.51 & 0.38 & 0.63 & 0.44 \\
\hline Item & 54 & 55 & 78 & & 50 & 42 & 70 \\
\hline Loading & 0.53 & 0.66 & 0.33 & & 0.25 & 0.60 & $0.12^{*}$ \\
\hline Item & 65 & 60 & 80 & & 59 & 49 & 79 \\
\hline Loading & 0.47 & 0.69 & 0.31 & & 0.66 & 0.41 & 0.34 \\
\hline Item & 69 & 64 & & & 62 & 52 & \\
\hline Loading & $0.03^{*}$ & 0.72 & & & 0.40 & 0.48 & \\
\hline Item & 72 & 75 & & & 71 & 59 & \\
\hline Loading & 0.55 & 0.72 & & & 0.59 & 0.50 & \\
\hline Item & 76 & 82 & & & 73 & 61 & \\
\hline Loading & 0.45 & 0.27 & & & 0.57 & 0.14 & \\
\hline Item & 83 & 84 & & & 81 & 74 & \\
\hline Loading & 0.35 & 0.35 & & & 0.55 & 0.34 & \\
\hline
\end{tabular}

NS novelty seeking, $H A$ harm avoidance, $R D$ reward dependence, $P$ persistence, $S D$ self-directedness, $C$ cooperativeness, $S T$ self-transcendence ${ }^{*} t$ test $<1.96$ (non significant loading) 
Table 3 Confirmatory factor analysis for the child-rated JTCI $(N=452)$

\begin{tabular}{|c|c|c|c|c|c|c|c|}
\hline & NS & $\mathrm{HA}$ & $\mathrm{RD}$ & $P$ & C & SD & ST \\
\hline Item & 6 & 1 & 20 & 5 & 2 & 3 & 12 \\
\hline Loading & 0.16 & 0.42 & 0.22 & 0.39 & 0.27 & 0.48 & 0.65 \\
\hline Item & 8 & 9 & 32 & 10 & 4 & 7 & 14 \\
\hline Loading & 0.21 & 0.48 & $0.03^{*}$ & 0.31 & 0.31 & 0.46 & 0.39 \\
\hline Item & 15 & 13 & 39 & 25 & 16 & 11 & 19 \\
\hline Loading & 0.30 & $0.01^{*}$ & 0.19 & 0.53 & $0.09^{*}$ & 0.55 & 0.18 \\
\hline Item & 21 & 17 & 44 & 40 & 22 & 18 & 23 \\
\hline Loading & 0.28 & 0.51 & 0.45 & 0.25 & 0.51 & 0.31 & 0.38 \\
\hline Item & 26 & 27 & 48 & 41 & 28 & 24 & 37 \\
\hline Loading & 0.13 & 0.14 & 0.25 & 0.54 & 0.58 & 0.15 & 0.33 \\
\hline Item & 30 & 31 & 63 & 45 & 33 & 29 & 53 \\
\hline Loading & 0.15 & $0.04^{*}$ & 0.36 & 0.53 & 0.46 & 0.61 & 0.60 \\
\hline Item & 43 & 35 & 67 & 57 & 36 & 34 & 56 \\
\hline Loading & 0.79 & 0.60 & 0.38 & 0.42 & 0.27 & $0.05^{*}$ & 0.31 \\
\hline Item & 51 & 47 & 68 & 77 & 46 & 38 & 66 \\
\hline Loading & 0.81 & 0.34 & 0.36 & 0.33 & 0.14 & 0.62 & 0.47 \\
\hline Item & 54 & 55 & 78 & & 50 & 42 & 70 \\
\hline Loading & 0.18 & 0.65 & $-0.03^{*}$ & & 0.17 & 0.45 & 0.17 \\
\hline Item & 65 & 60 & 80 & & 59 & 49 & 79 \\
\hline Loading & 0.11 & 0.64 & 0.28 & & 0.50 & 0.16 & 0.63 \\
\hline Item & 69 & 64 & & & 62 & 52 & \\
\hline Loading & $-0.02^{*}$ & 0.60 & & & 0.39 & 0.33 & \\
\hline Item & 72 & 75 & & & 71 & 58 & \\
\hline Loading & $0.09^{*}$ & 0.60 & & & 0.40 & 0.55 & \\
\hline Item & 76 & 82 & & & 73 & 61 & \\
\hline Loading & 0.31 & 0.36 & & & 0.47 & 0.15 & \\
\hline Item & 83 & 84 & & & 81 & 74 & \\
\hline Loading & 0.21 & 0.34 & & & 0.70 & $0.01^{*}$ & \\
\hline
\end{tabular}

NS novelty seeking, HA harm avoidance, $R D$ reward dependence, $P$ persistence, $S D$ self-directedness, $C$ cooperativeness, $S T$ self-transcendence ${ }^{*} t$ test $<1.96$ (non significant loading)

used as an indicator of fit with a threshold value of 2.5 .

Because $\chi^{2}$ is size dependant another criteria was used; the Goodness of Fit Index estimates the extent to which the sample covariances are reproduced by the hypothesized model. A value of GFI exceeding 0.90 and a RMSEA below 0.50 are generally considered as criterias of a good fit between the theoretical model and the data.

JTCI parents-rated questionnaire fit parameters were: $N=243$, GFI $=0.56, \chi^{2}=7195.75, d f=3381$, $\chi^{2} / d f<2.50$, and RMSEA $=1.00$. JTCI child-rated questionnaire Fit parameter were: $N=452$, GFI $=0.67, \chi^{2}=7475.09, \chi^{2} / d f<2.50$, and RMSEA $=0.80$. GFI was $<0.90$ and RMSEA $>0.5$ for both parent and child-rated versions, thus below standard criteria, whereas in both versions $\chi^{2} / d f$ values were above usual fit criteria.

In the parent-rated version, all items of $\mathrm{P}, \mathrm{C}$ and SD dimensions showed t-tests above 1.96. Four items did not load on the hypothesized factor: NS item 69 : "He (she) takes part immediately when someone proposes interesting projects", HA item 27: "My child is very cautious and pays attention to undesirable events (e.g. keeping himself warm or not harming himself (herself)", RD item 48: "He (she) prefers to solve the problems by himself (herself)", and ST item 70: "When he (she) is engrossed in his (her) activities, he (she) can forget anything else".

For the children version t-test values were above 1.96 for all items of P and ST. Nine items did not load on the hypothesized factor: 2 items of the dimensions NS (item 69: "I take part immediately when someone proposes interesting projects" and item 72: "I usually love doing new or unusual things"), HA (items 13: "I love meeting new people" and 31: "I am not afraid of singing in front of others at a party or playing theatre" ), RD (item 32: I am lonely" and item 78: "I do not like to talk about myself") SD (items 34: "I love suggesting how to improve things" and 74: "Most of the time I clearly know what I'm looking for (e.g.: achieving good results at school, meeting new friends, or saving money to buy something I want") and for one item in C (16: "I quickly get impatient when someone does not do or does not understand things").

\section{Correlations among JTCI scores}

Results are presented in Table 4. Significant correlations were found between the three temperament and the four character scores. 
Table 4 Relations among subscales in the parents and child-rated JTCI

\begin{tabular}{|c|c|c|c|c|c|c|c|c|c|c|c|c|}
\hline & \multicolumn{2}{|l|}{ NS } & \multicolumn{2}{|l|}{ HA } & \multicolumn{2}{|l|}{$\mathrm{RD}$} & \multicolumn{2}{|l|}{$P$} & \multicolumn{2}{|l|}{ SD } & \multicolumn{2}{|l|}{ C } \\
\hline & JTCI-P & JTCl-C & JTCI-P & JTCl-C & JTCI-P & JTCI-C & JTCI-P & JTCl-C & JTCI-P & JTCI-C & JTCI-P & JTCI-C \\
\hline $\mathrm{RD}$ & & & -0.26 & & & & & & & & & \\
\hline$P$ & -0.42 & -0.38 & & & 0.18 & & & & & & & \\
\hline SD & & -0.22 & -0.43 & -0.44 & 0.12 & & 0.58 & 0.32 & & & & \\
\hline C & -0.46 & -0.35 & -0.16 & & 0.50 & 0.41 & 0.46 & 0.36 & 0.37 & & & \\
\hline ST & & & & 0.23 & & & & 0.15 & & & 0.23 & 0.22 \\
\hline
\end{tabular}

JTCI-P parent-rated junior temperament and character inventory, JTCI-C child-rated junior temperament and character inventory, NS novelty seeking, HA harm avoidance, $R D$ reward dependence, $P$ persistence, SD self-directedness, $C$ cooperativeness, ST self-transcendence

Only significant correlations are shown $(P<0.05)$

Table 5 Correlations between JTCl dimensions and scores of psychopathology

\begin{tabular}{|c|c|c|c|c|c|c|c|c|c|c|c|c|c|c|}
\hline & \multicolumn{2}{|l|}{ NS } & \multicolumn{2}{|l|}{ HA } & \multicolumn{2}{|l|}{$\mathrm{RD}$} & \multicolumn{2}{|l|}{$P$} & \multicolumn{2}{|l|}{ SD } & \multicolumn{2}{|l|}{ C } & \multicolumn{2}{|l|}{ ST } \\
\hline & JTCI-P & JTCl-C & JTCI-P & JTCI-C & JTCI-P & JTCI-C & JTCI-P & JTCl-C & JTCI-P & JTCI-C & JTCI-P & JTCI-C & JTCI-P & JTCI-C \\
\hline CBCL Int & 0.15 & & 0.45 & 0.19 & -0.17 & & -0.15 & & -0.39 & & -0.16 & & & \\
\hline CBCL Ext & 0.43 & 0.20 & 0.17 & & & & -0.30 & & -0.40 & & -0.36 & & & \\
\hline CBCL Total & 0.34 & 0.16 & 0.30 & & -0.14 & & -0.25 & & -0.40 & & -0.29 & & & \\
\hline
\end{tabular}

JTCI-P parent-rated junior temperament and character inventory, JTCI-C child-rated junior temperament and character inventory, NS novelty seeking; HA harm avoidance, $R D$ reward dependence, $P$ persistence, SD self-directedness, $C$ cooperativeness, ST self-transcendence

Only significant correlations are presented $(P<0.05)$

In the parents version, high negative correlations were found between NS, P and C, HA and SD, and positive correlations were shown between $C, R D$ and $\mathrm{P}$, as well as between $\mathrm{P}$ and SD.

In the children version, negative correlations were found between $\mathrm{HA}$ and SD, and positive correlations were shown between $\mathrm{C}$ and RD.

\section{Correlations between JTCl, EAS and CBCL}

For the parents rated questionnaires, the highest correlations between JTCI and EAS were found for the following dimensions: emotionality, NS and HA (respectively $r=0.34$ and $r=0.33$ ), shyness and HA $(r=0.47)$, sociability and RD $(r=0.46)$. Negative correlations were found between Activity and HA $(r=-0.36)$, Shyness and SD $(r=-0.32)$.

For the children-rated questionnaires, the highest correlations between JTCI and EAS were found for HA, emotionality $(r=0.41)$ and shyness $(r=0.42)$, $\mathrm{RD}$ and sociability $(r=0.49)$, Activity, $\mathrm{P}(r=0.30)$ and SD $(r=0.36)$. Significant negative correlations were found between SD and Emotionality $(r=-0.32)$, as well as between HA and Activity $(r=-0.36)$.

Total CBCL scores were significantly linked to all temperament and character scores, except self-transcendence. Highest correlations were found for total CBCL and SD $(r=-0.40)$ and total CBCL and NS $(r=0.30)$. CBCL externalized scores were positively correlated with NS scores $(r=0.43)$ and negatively with $\mathrm{P}, \mathrm{SD}$ and $\mathrm{C}$ (respectively $r=-0.3,-0.4,-0.36$ ). CBCL internalized scores were correlated with HA $(r=0.45)$ and SD $(r=-0.39)$. Details for the CBCL/ JTCI correlations are given in Table 5.

\section{Discussion}

In the current study, the psychometric properties of a French parent- and child-rated questionnaire adapted from the junior temperament and character inventory (JTCI) were assessed in a sample of 452 French children for the child-rated JTCI and in 233 children for the parent-rated JTCI. We explored consistency, external validity and performed a factorial analysis (confirmatory analysis) of this instrument.

The present work assessed the validity of both child and parent versions of the JTCI, allowing comparison of psychometric characteristics of the two versions. Our results indicate that the internal validity estimates of the parent version were consistently higher than those of the child version in all dimensions of the questionnaire, with the exception of ST. Lower internal consistencies were also reported for child-rated JTCI by Copeland [14] in a comparison between mother-reports and child-reports of the JTCI. 
This suggests that the parent version is generally more stable than the child-rated one. The French child-rated JTCI is not suitable for clinical practice in its present form due to its inadequate psychometric performance. To explain this finding, we hypothesize that the children's perception of their reactivity and functioning may be more variable than their parents' perception. The younger age of our sample (mean age 12.9) compared with the population used for the German JTCI 12-18 might also account for the low internal consistency of temperament and character dimensions in the child-rated questionnaire. To explore this issue, we plan to obtain further data from older adolescents. However, to make the child version suitable for young adolescents, thorough modifications are necessary to improve reliability of measurements. Examining semantic/phrasing of the items, content issues and item analysis based on our current psychometric analysis (e.g. modify items with low or incongruent factor loadings) could be useful to this purpose. Parameters of consistency obtained in our sample are, in general, close to those reported in previous reports. In particular, the low values of Cronbach $\alpha$ values of $\mathrm{RD}$ in both child and parentrated questionnaires has been found in previous pediatric and adult samples [34, 37, 49]. Lack of stability of RD may be accounted for by the limited number of items in this dimension. Moreover, we found low Cronbach $\alpha$ values of NS in the child-rated JTCI, and ST in the parents' version (respectively, 0.52 and 0.56). This suggests that adolescents may find it difficult to assess novelty seeking behaviour, while parents may find it particularly difficult to assess their children's spiritual believes. It is also noteworthy that the range of our Cronbach $\alpha$ values was relatively low compared to the French version of the TCI [37]. This finding was also reported by Lyoo et al. comparing the validity of their Korean JTCI and the TCI [49]. As suggested by Lyoo et al., this may be due to the fact that the JTCI has fewer items than the adult TCI. Alternatively, it is possible that larger variances in personality measures may be explained by the emotional and developmental changes which occur during adolescence. Low internal consistency was also found for "fantasy", a sub-scale of ST, in a sample of children with externalized behaviour and their siblings in both self-reported and mother-reported JTCI [14]. As for correlations among dimension scores, our results (i.e. significant negative correlations between NS and $\mathrm{P}, \mathrm{HA}$ and SD, P and SD) are consistent with those reported by Lyoo et al. [49] in their child and adolescent sample. Correlational analyses of the TCI dimensions in adults show somewhat different results [37]. We can hypothesize that the relationships among dimensions change with the psychological development of an individual. However, the signifi- cant negative correlation between $\mathrm{HA}$ and SD seems to be stable over time and across different countries, since it was found in previous studies of both TCI and JTCI [21, 34, 35, 37]. This correlation was also found in a sample of preschool children (aged 2-5 years) as reported by Constantino et al. [13] and in the sibling sample of Copeland et al. [14].

With regard to inter-scale correlations, an estimate of parent-child agreement, the lowest values were found for the ST dimension, suggesting that the dimension linked to spiritual believes is differently assessed by parents and adolescents. This may be explained by the fact that parent's knowledge of their children's spiritual life may be very limited but findings related to ST should be interpreted with caution because of the low consistency of this scale. More generally, dimensions having a behavioral expression (e.g., NS and C) yielded higher parent-child correlations than those without (e.g. ST). This trend was also found in parent-child correlations of the EAS temperament dimensions where activity was the dimension with the highest agreement [19].There are similar findings for informant correspondence in children's psychopathology: parent-child correlations are higher for externalized behaviors than for internalized symptoms [29]. Compared with the low mean parentchild correlation $(r=0.25)$ reported in a meta-analysis of cross-informant correlations in childhood emotional and behavioral problems [2], our findings support convergent validity of the JTCI.

As for sex differences in temperament and character scores, the finding of significantly higher HA, $\mathrm{RD}, \mathrm{ST}$ scores in girls seems to be developmentally stable since it was reported also by Pelissolo et al. in their adult sample [37].

We did not find significant age effects on temperament and character scores in our sample, suggesting that those traits are relatively stable during teenage period.

The CFA revealed that most of the indices of fit were below the standard criteria and that several items (in particular in NS, HA, RD) did not load significantly on the a priori factors. This result indicates that the data collected does insufficiently support the theoretical model. Poor fit may be due to some items measuring multiple factors or stronger relationships between some items within a factor. Another possible explanation for the low fit between the data and the model is possibly related to the successive changes carried out in the German validation studies (e.g., item modification and deletion) and in our pilot study. It is to note that most of the rare CFA studies of the adult TCI, using the whole items as indicators of scales, failed to confirm the theoretical structure of the questionnaires [18, 44]. Compared to these studies in adults, the CFA indices 
that we obtained for the parent-rated JTCI were similar or even better.

Relationships between JTCI dimensions and psychopathology show consistent patterns across studies. In our study, externalized problems were positively correlated with NS. This is in line with previous findings pointing to an association between novelty seeking behaviors and disruptive disorders [14, 38, 40]. It has been suggested that an insufficient dopamine-related natural reward may lead to the use of 'unnatural' immediate rewards, such as substance use, gambling, risk taking and inappropriate eating (namely the"reward deficiency syndrome" hypothesis) $[16,45-48]$. Harm avoidance was positively correlated with internalized problems. This is consistent with the results of previous reports $[7,12,24,26,28$, 38]. HA and NS were the only dimensions positively correlated with CBCL subscores. All other JTCI dimensions were negatively correlated with CBCL scores. In particular, SD was negatively correlated with all subscales of the CBCL. This suggests that low SD may be a non specific indicator of psychopathology and that, in turn, high SD may carry a protective role. Longitudinal investigations are needed to further clarify relationships between personal maturity and psychopathology and to assess direction of causality [37].

\section{Limitations}

The results of our study should be considered in light of several limitations. First, the JTCI used in this study was not translated from the original instrument but from a previous German version. Second, the age range was relatively limited (10-16 years). Third, data on parent rated JTCI, EAS, and CBCL was not avail- able in one of the two samples included in this study. Fourth, in our main sample $(N=243)$, the proportion of girls $(63.4 \%)$ was higher than that of boys (36.6\%). However, our findings on gender differences in JTCI dimensions scores were similar to those reported in the literature and, therefore, the sex ratio of the present study seems not to introduce a significant bias.

\section{Conclusion}

This is the first study that examined the psychometric properties of a French version of the JTCI including both child and parent-reports. Assessments included the EAS, a questionnaire based on a temperament model largely used in children, to examine external validity of the JTCI as well as a measure of general psychopathology. Temperament and character dimensions of the JTCI both correlated with dimensions of the Emotionality Sociability Activity model of temperament and symptoms of psychopathology (as assessed by the CBCL).

Our results showed significant differences in the psychometric qualities between child and parentrated versions. Most temperament and character dimensions of the parent-rated JTCI had satisfactory internal consistency but the low fit between the data and the theoretical model warrants further investigation. On the other hand, the low consistencies found in the child-rated JTCI indicate that the current version is not stable enough in its current form.

Acknowledgments D. Purper-Ouakil received a grant from the "Assistance Publique/ Hôpitaux de Paris (PHRC AOR 03006). We thank Prof. Cloninger, Prof. Schmeck and Dr. Goth for their help, as well as Dr. Paul Bain, Mrs. Aston, the "Rectorat de l'Isère" and the students of the College de L'Isle (38).

\section{References}

1. Achenbach TM, Edelbrock C (1983) Manual for the child behavior checklist and revised child behavior profile

2. Achenbach TM, McConaughy SH, Howell CT (1987) Child/adolescent behavioral and emotional problems: implications of cross-informant correlations for situational specificity. Psychol Bull 101:213-232

3. Becker K, El-Faddagh M, Schmidt MH, Laucht M (2007) Is the serotonin transporter polymorphism (5HTTLPR) associated with harm avoidance and internalising problems in childhood and adolescence? J Neural Transm 114:395-402
4. Boer F, Westenberg PM (1994) The factor structure of the Buss and Plomin EAS temperament survey (parental ratings) in a Dutch sample of elementary school children. J Pers Assess 62:537-551

5. Brandstrom S, Richter J, Przybeck T (2001) Distributions by age and sex of the dimensions of temperament and character inventory in a cross-cultural perspective among Sweden, Germany, and the USA. Psychol Rep 89:747-758

6. Buss AH, Plomin R (1986) The EAS approach to temperament. In: P1omin $\mathrm{R}$, Dunn J (eds) The study of temperament: changes, continuities and challenges, pp.67-79
7. Chien AJ, Dunner DL (1996) The tridimensional personality questionnaire in depression: state versus trait issues. J Psychiatr Res 30:21-27

8. Chotai J, Jonasson M, Hagglof B, Adolfsson R (2002) The temperament scale of novelty seeking in adolescents shows an association with season of birth opposite to that in adults. Psychiatry Res 111:45-54

9. Cloninger CR (2004) Feeling good: The science of well-being. Oxford

10. Cloninger CR, Przybek TR, Svracik DM, Wetzel RD (1994) The temperament and character inventory. A guide to its development and use. Center for psychobiology of personality, Washington University, St Louis, MO 
11. Cloninger CR, Svrakic DM, Przybeck TR (1993) A psychobiological model of temperament and character. Arch Gen Psychiatry 50:975-990

12. Cloninger CR, Svrakic DM, Przybeck TR (2006) Can personality assessment predict future depression? A twelvemonth follow-up of 631 subjects. J Affect Disord 92:35-44

13. Constantino JN, Cloninger CR, Clarke AR, Hashemi B, Przybeck T (2002) Application of the seven-factor model of personality to early childhood. Psychiatry Res 109:229-243

14. Copeland W, Landry K, Stanger C, Hudziak JJ (2004) Multi-informant assessment of temperament in children with externalizing behavior problems. J Clin Child Adolesc Psychol 33:547-556

15. Dor E, Pélissolo A, Purper-Ouakil D, Flament M, Mouren-Siméoni MC, Lépine JP (2000) Adaptation of the temperaament and character inventory (TCI) for children. Eur Psychiatry 15(Suppl1):46

16. Ebstein RP, Novick O, Umansky R, Priel B, Osher Y, Blaine D, Bennett ER, Nemanov L, Katz M, Belmaker RH (1996) Dopamine D4 receptor (D4DR) exon III polymorphism associated with the human personality trait of Novelty Seeking. Nat Genet 12:78-80

17. Fombonne E, Chehdan F, Carradec AM, Achard S, Navarro N, Reiss S (1988) Le Child Behavior Checklist : un instrument pour la recherche en psychiatrie de l'enfant. Psychiatrie et Psychobiologie 3: 409-418

18. Gana K ,Trouillet R (2003) Structure invariance of the temperament and character inventory (TCI). Pers Individ Dif 35: 1483-1495

19. Gasman L, Purper-Ouakil D, Michel G, Mouren-Simeoni MC, Bouvard M, Perez-Diaz F, Jouvent R (2002) Crosscultural assessment of childhood temperament. A confirmatory factor analysis of the French emotionality activity and sociability (EAS) questionnaire. Eur Child Adolesc Psychiatry 11:101107

20. Gillespie NA, Cloninger CR, Heath AC, Martin NG (2003) The genetic and environmental relationship between Cloninger's dimensions of temperament and character. Pers Individ Dif 35: 1931-1946

21. Goth K, Schmeck K (1999) A German version of the junior temperament and character Inventory. Eur Child Adolesc Psychiatry 8(Suppl 2):175

22. Gothelf D, Aharonovsky O, Horesh N, Carty T, Apter A (2004) Life events and personality factors in children and adolescents with obsessive-compulsive disorder and other anxiety disorders. Compr Psychiatry 45:192-198
23. Gutierrez-Zotes JA, Bayon C, Montserrat C, Valero J, Labad A, Cloninger CR, Fernandez-Aranda F (2004) Temperament and character inventory revised (TCI-R). Standardization and normative data in a general population sample. Actas Esp Psiquiatr 32:8-15

24. Hansenne M, Reggers J, Pinto E, Kjiri K, Ajamier A, Ansseau M (1999) Temperament and character inventory (TCI) and depression. J Psychiatr Res 33:31-36

25. Hatcher, Larry (1994) A step-by-step approach to using the SAS system for factor analysis and structural equation modeling, p 588

26. Howard MO, Kivlahan D, Walker RD (1997) Cloninger's tridimensional theory of personality and psychopathology: applications to substance use disorders. J Stud Alcohol 58:48-66

27. INSEE (2005) Available at http://www.insee.fr/en/nom_def_met/ nomenclatures/pcs.htm

28. Kim SJ, Lee SJ, Yune SK, Sung YH, Bae SC, Chung A, Kim J, Lyoo IK (2006) The relationship between the biogenetic temperament and character and psychopathology in adolescents. Psychopathology 39:80-86

29. Kolko DJ, Kazdin AE (1993) Emotional/behavioral problems in clinic and nonclinic children: correspondence among child, parent and teacher reports. J Child Psychol Psychiatry 34:991-1006

30. Kuo PH, Chih YC, Soong WT, Yang HJ, Chen WJ (2004) Assessing personality features and their relations with behavioral problems in adolescents: tridimensional personality questionnaire and junior eysenck personality questionnaire. Compr Psychiatry 45:20-28

31. Laucht M, Becker K, Blomeyer D, Schmidt MH (2007) Novelty seeking involved in mediating the association between the dopamine D4 receptor gene exon III polymorphism and heavy drinking in male adolescents: results from a high-risk community sample. Biol Psychiatry 61:87-92

32. Laucht M, Becker K, El-Faddagh $M$, Hohm E, Schmidt MH (2005) Association of the DRD4 exon III polymorphism with smoking in fifteen-yearolds: a mediating role for novelty seeking?. J Am Acad Child Adolesc Psychiatry 44:477-484

33. Laucht M, Becker K, Schmidt MH (2006) Visual exploratory behaviour in infancy and novelty seeking in adolescence: two developmentally specific phenotypes of DRD4?. J Child Psychol Psychiatry 47:1143-1151
34. Luby JL, Svrakic DM, McCallum K, Przybeck TR, Cloninger CR (1999) The Junior Temperament and Character Inventory: preliminary validation of a child self-report measure. Psychol Rep 84:1127-1138

35. Lyoo IK, Han $\mathrm{CH}$, Lee SJ, Yune SK, Ha JH, Chung SJ, Choi H, Seo CS, Hong KE (2004) The reliability and validity of the junior temperament and character inventory. Compr Psychiatry 45:121128

36. Marsh HW, Balla JR, McDonald RP (1988) Goodness-of-fit indexes in confirmatory factor analysis. The effect of sample size. Psychol Bull 103: 391-410

37. Pelissolo A, Lepine JP (2000) Normative data and factor structure of the temperament and character inventory (TCI) in the French version. Psychiatry Res 94:67-76

38. Rettew DC, Stanger C, McKee L, Doyle A, Hudziak JJ (2006) Interactions between child and parent temperament and child behavior problems. Compr Psychiatry 47:412-420

39. SAS Institute Inc. (1989) SAS, STAT ${ }^{\circledR}$ Users Guide, Version 6, voI 2. SAS Institute Inc, Cary, NC, USA

40. Schmeck K, Poustka F (2001) Temperament and disruptive behavior disorders. Psychopathology 34:159-163

41. Stadler C, Sterzer P, Schmeck K, Krebs A, Kleinschmidt A, Poustka F (2007) Reduced anterior cingulate activation in aggressive children and adolescents during affective stimulation: association with temperament traits. J Psychiatr Res 41:410-417

42. Svrakic DM, Przybeck TR, Cloninger CR (1991) Further contribution to the conceptual validity of the unified biosocial model of personality: US and Yugoslav data. Compr Psychiatry 32:195-209

43. Tillman R, Geller B, Craney JL, Bolhofner K, Williams M, Zimerman B, Frazier J, Beringer L (2003) Temperament and character factors in a prepubertal and early adolescent bipolar disorder phenotype compared to attention deficit hyperactive and normal controls. J Child Adolesc Psychopharmacol 13:531-543

44. Tomita T, Aoyama H, Kitamura T, Sekiguchi C, Murai T, Matsuda T (2000). Factor structure of psychobiological seven-factor model of personality: a model-revision. Personality Individ Diff 29:709-727

45. Tomitaka M, Tomitaka S, Otuka Y, Kim K, Matuki H, Sakamoto K, Tanaka A (1999) Association between novelty seeking and dopamine receptor D4 (DRD4) exon III polymorphism in Japanese subjects. Am J Med Genet 88:469-471 
46. Wang S, Mason J, Charney D, Yehuda R, Riney S, Southwick S (1997) Relationships between hormonal profile and novelty seeking in combat-related posttraumatic stress disorder. Biol Psychiatry 41:145-151

47. Wiesbeck GA, Mauerer C, Thome J, Jakob F, Boening J (1995) Neuroendocrine support for a relationship between "novelty seeking" and dopaminergic function in alcoholdependent men. Psychoneuroendocrinology 20:755-761
48. Wills TA, Vaccaro D, McNamara G (1994) Novelty seeking, risk taking, and related constructs as predictors of adolescent substance use: an application of Cloninger's theory. J Subst Abuse 6:1-20
49. Yoo HJ, Kim M, Ha JH, Chung A, Sim ME, Kim SJ, Lyoo IK (2006) Biogenetic temperament and character and attention deficit hyperactivity disorder in Korean children. Psychopathology 39:25-31 